\title{
Evaluation of analgesic activity of the methanol extract from the galls of Quercus infectoria alone and as an adjuvant in wistar rats
}

\author{
Abishek P. Raichurkar, Shashikala Gowdara Hanumanth Reddy*
}

Department of Pharmacology, JJM Medical College, Davangere, Karnataka, India

\author{
Received: 10 March 2020 \\ Accepted: 27 March 2020 \\ *Correspondence: \\ Dr. Shashikala Gowdara Hanumanth Reddy, \\ Email: shashikalagh28@gmail.com
}

Copyright: (C) the author(s), publisher and licensee Medip Academy. This is an open-access article distributed under the terms of the Creative Commons Attribution Non-Commercial License, which permits unrestricted non-commercial use, distribution, and reproduction in any medium, provided the original work is properly cited.

\begin{abstract}
Background: Non-steroidal anti-inflammatory drugs and opioids are the most preferred drugs for pain relief. Considering the gastrointestinal toxicity, dependence and other side effects, search for better analgesic drug continues. Quercus infectoria (QI) is from the family Fagaceae. The galls of QI are comprised of tannin (36 to 60\%), gallic acid, ellagic acid, and syringic acid. They possess antioxidant, anti-inflammatory, antimicrobial, and antidiabetic properties. In India, galls of QI have been used for the treatment of toothache, diarrhoea, sore throat and inflammatory diseases as a home remedy. This study was conducted to evaluate the analgesic activity of methanolic extract of galls of QI on wistar rats using tail-flick and Eddy's hot-plate methods. The objective of the study was to evaluate the analgesic activity of methanolic extract of galls of QI alone and as an adjuvant with tramadol on Wistar rats.

Methods: Total of 24 wistar rats were included in the study and divided into 4 groups. They received drugs intraperitoneally as follows. In group 1, normal saline, in group 2, tramadol, in group 3, methanolic extract of galls of QI and in group 4, tramadol with methanolic extract of galls of QI was available.

Results: Methanolic extract of galls of QI produced significant maximal possible analgesia $(<0.001)$ at 30 and 60 minutes in tail-flick method whereas it failed to produce analgesia in hot-plate method during all time intervals.

Conclusions: Methanolic extract of galls of QI showed analgesic activity in tail-flick method indicating that its possible mechanism of action is spinally mediated.
\end{abstract}

Keywords: Galls of Quercus infectoria, Analgesic, Tail flick method, Eddy's hot plate method

\section{INTRODUCTION}

Pain can be defined as a disagreeable, sensory and arousing experience coupled by real or potential tissue damage. ${ }^{1}$ Analgesics are the drugs that relieve pain. They are mainly classified as opioid and non-opioid which act centrally and peripherally respectively. ${ }^{2}$

Long-term use of non-steroidal anti-inflammatory drugs (NSAIDs) leads to gastrointestinal toxicity like gastric and duodenal ulcer and adverse effects such as dependence, tolerance and addiction occur with the use of opiates. ${ }^{3}$ Hence, search for newer and safer analgesic drugs is ongoing.

Many herbs, throughout the history, have been used for pain management with minimal adverse effects. ${ }^{4}$ Quercus infectoria (QI) (Olivier) is commonly known as gall oak, which is a small shrub with 4-6 feet height, found mainly in Greece, Cyprus, Persia, Iran and Turkey. In Asia, QI has been used since ages as a traditional medication. ${ }^{5}$

The galls arising in the branches of the tree is called "Majuphal" in Sanskrit and "Machakai" in Kannada. ${ }^{6.7}$ 
The gall extract of QI is extensively used as an ingredient for preparation of traditional medicines which are used to treat conditions like phthisis, cough, asthma, dysentery, skin diseases, menorrhagia, intestinal haemorrhage, eczema, impetigo, chronic diarrhoea and trichomoniasis. ${ }^{8}$

Pharmacologically, it has been documented to possess astringent, anti-inflammatory, antimicrobial, antidiabetic, larvicidal, anti-ulcerogenic and gastroprotective activitiies. ${ }^{9-14}$

There are limited studies in regard to the analgesic activity of galls of QI. Hence, this study was taken up to evaluate the analgesic activity of methanolic extract of the galls of QI when given alone and as an adjuvant with tramadol.

\section{Objective}

The objective of the study was to evaluate the analgesic activity of methanolic extract of galls of QI in wistar rats and to evaluate its analgesic effect when given as an adjuvant with tramadol.

\section{METHODS}

\section{Selection of animals}

Wistar rats were obtained from Animal House attached to Department of Pharmacology, JJM Medical College, Davangere. Total 24 rats, weighing 150 to $200 \mathrm{gm}$ of either sex were taken. Animals were fed standard pellet diet and water.

They were acclimatized for 7 days before commencement of study in standard laboratory condition 12 hours day and night rhythm, maintained at $25 \pm 30{ }^{\circ} \mathrm{C}$ and 50 to $70 \%$ humidity. This study was conducted after obtaining ethical clearance JJMMC/IAEC/15-2017 and was conducted for a duration of 4 weeks.

Healthy wistar rats of either sex weighing 150-200 gm and which were previously unused were included in the study. Pregnant and diseased rats were not included in the study. The drugs and chemicals used were normal saline $(10 \mathrm{ml} / \mathrm{kg})$, methanolic extract of galls of QI $(20 \mathrm{mg} / \mathrm{kg})$ and tramadol $(10 \mathrm{mg} / \mathrm{kg})$.

\section{Procedure}

Extraction procedure: Methanolic extract of galls of QI was extracted using cold extraction technique. ${ }^{15}$ Here, 100 grams of galls of QI powder was immersed in methanol $(500 \mathrm{ml})$ for a period of 24 hours at room temperature. The mixture was then filtered and the process was repeated using remaining residue with methanol. Both the filtrates were combined and concentrated using rotatory evaporator and the semi-solid residue was introduced to hot air dryer to obtain powdery, crude methanolic extract. ${ }^{15}$
The animals were divided into 4 groups of 6 rats each. Group I animals received normal saline $10 \mathrm{ml} / \mathrm{kg}$ and considered as control. Group II animals received tramadol $10 \mathrm{mg} / \mathrm{kg}$ intraperitoneally and considered as standard. Group III animals received methanolic extract of the galls of QI (20 mg/kg) intraperitoneally. Group IV animals received methanolic extract of the galls of QI with standard $(20 \mathrm{mg} / \mathrm{kg}$ and $10 \mathrm{mg} / \mathrm{kg})$ intraperitoneally.

Analgesic activity was assessed by tail flick method, Eddy's hot plate method.

\section{Tail flick method}

Analgesia was measured using modified method of D Amour and Smith called as tail flick method using an analgesiometer. Reaction time (latency time) in seconds was used as the unit for measurement of pain and an increase in reaction time was indicative of analgesia. Time between placing the tail of the rat on the radiant heat source and sharp withdrawal of the tail was recorded as "reaction time". Cut off time of ten seconds was imposed in all sets of experiments taken as maximum latency so as to rule out thermal injury while noting down the reaction time. In all the groups, tail-flick test was performed prior to drug administration, and at 30,60 and 90 minutes after drug administration and the reaction time at each time interval (test latency) was calculated. ${ }^{15}$

The maximal possible analgesia (MPA) was calculated as follows:

$$
\mathrm{MPA}=\frac{\text { Reaction time for treatment }- \text { basal reaction time }}{\text { maximum latency }- \text { basal reaction time }} \times 100^{1}
$$

\section{Eddy's hot plate method}

The hot plate consists of an electrically heated surface. The temperature is controlled at $55^{\circ}$ to $56^{\circ} \mathrm{C}$. This can be a copper plate or a heated glass surface. The animals are placed on the hot plate and the time until either licking or jumping occurs is recorded by a stop-watch. The latency is recorded before and after 30,60 and 90 min after drug administration. ${ }^{15}$

The MPA was calculated as follows:

$\mathrm{MPA}=\frac{\text { Reaction time for treatment }- \text { basal reaction time }}{\text { maximum latency }- \text { basal reaction time }} \times 100^{1}$

\section{Statistical analysis}

The data was analyzed with Statistical Package for Social Sciences (SPSS) for Windows 25.0 (SPSS, Inc. Chicago, Illinois). Reaction time for treatment and basal reaction time were expressed as mean \pm standard error mean (SEM). Then the percentage of maximum possible analgesia was calculated. Student's t-test was performed to determine statistical significance and values of $\mathrm{p}<0.05$ were interpreted as statistically significant. 


\section{RESULTS}

\section{Tail flick model}

The mean values of the reaction times (in seconds) observed in all 4 groups at the different time intervals are as shown in Table 1. Table 2 show that when compared to the control group, all other groups showed significantly higher percentage of MPA at all time intervals. The MPA achieved by the extract was less than tramadol. The combination group elicited the highest percentage of MPA.

\section{Eddy's hot plate}

The mean values of the reaction times (in seconds) observed in all 4 groups using Eddy's hot plate method at the different time intervals are as shown in Table 3. Table 4 show the percentage of MPA achieved by the test groups. In the hot plate method, the extract failed to elicit analgesic activity. Analgesic activity was observed only in the tramadol and combination groups as seen in Table 4.

Table 1: Mean values of reaction times (in seconds) in tail flick model (mean \pm SEM).

\begin{tabular}{|lllll|}
\hline Time & Group I & Group II & Group III & Group IV \\
\hline Basal & $3.31 \pm 0.63$ & $2.63 \pm 0.62$ & $3.03 \pm 0.28$ & $3.06 \pm 0.23$ \\
\hline $\mathbf{3 0}$ min & $2.96 \pm 0.18$ & $6.10 \pm 0.59^{* x}$ & $5.66 \pm 0.43^{* x}$ & $7.06 \pm 0.35^{* x y z}$ \\
\hline 60 min & $3.06 \pm 0.25$ & $5.83 \pm 0.57^{* \mathrm{x}}$ & $4.76 \pm 0.46^{* \mathrm{x}}$ & $5.91 \pm 0.52^{* \mathrm{xy}}$ \\
\hline $\mathbf{9 0}$ min & $2.96 \pm 0.10$ & $5.76 \pm 0.51^{* \mathrm{*}}$ & $3.83 \pm 0.18^{* \mathrm{x}}$ & $5.51 \pm 0.31^{* \mathrm{xy}}$ \\
\hline
\end{tabular}

All values by Student's $t$-test, significant at $\mathrm{p}<0.05$, and $\mathrm{SEM}=$ standard error mean. ${ }^{*} \mathrm{p}<0.05$ versus baseline of the respective treatment, ${ }^{\mathrm{x}} \mathrm{p}<0.05$ treatment versus control, extract versus tramadol was not significant at all time points, ${ }^{\mathrm{y}} \mathrm{p}<0.05$ extract versus tramadol and extract, ${ }^{\mathrm{z}} \mathrm{p}<0.05$ tramadol versus tramadol and extract.

Table 2: Mean values of maximal possible analgesia (mean \pm SEM) in tail flick model.

\begin{tabular}{|lllll|}
\hline Time & Group 1 & Group 2 & Group 3 & Group 4 \\
\hline 30 min & - & $46.83 \pm 8.52^{*}$ & $37.84 \pm 5.0^{*}$ & $56.64 \pm 6.79^{*} \mathrm{yz}$ \\
\hline 60 $\mathbf{m i n}$ & - & $43.27 \pm 7.98^{* \mathrm{x}}$ & $24.86 \pm 6.12^{*}$ & $40.92 \pm 8.63^{* \mathrm{y}}$ \\
\hline $\mathbf{9 0}$ min & - & $42.30 \pm 7.50^{* \mathrm{x}}$ & $11.35 \pm 4.64^{*}$ & $35.20 \pm 5.87^{*} \mathrm{y}$ \\
\hline
\end{tabular}

All values by Student's $t$-test, significant at $\mathrm{p}<0.05$, and $\mathrm{SEM}=$ standard error mean. ${ }^{*} \mathrm{p}<0.05$ treatment versus control, ${ }^{\mathrm{x}} \mathrm{p}<0.05$ extract versus tramadol, ${ }^{\mathrm{y}} \mathrm{p}<0.05$ extract versus tramadol and extract, ${ }^{\mathrm{p}} \mathrm{p}<0.05$ tramadol versus tramadol and extract.

Table 3: Mean values of reaction times (in seconds) in Eddy's hot plate (mean \pm SEM).

\begin{tabular}{|lllll|}
\hline Time & Group 1 & Group 2 & Group 3 & Group 4 \\
\hline Basal & $2.77 \pm 0.78$ & $2.57 \pm 0.43$ & $2.43 \pm 0.50$ & $2.62 \pm 0.54$ \\
\hline 30 min & $2.48 \pm 0.45$ & $5.35 \pm 0.38^{* x y}$ & $3.28 \pm 0.52$ & $5.1 \pm 0.23^{* x z}$ \\
\hline 60 min & $2.80 \pm 0.19$ & $5.10 \pm 0.24^{* x y}$ & $3.15 \pm 0.27$ & $4.81 \pm 0.24^{* \times x}$ \\
\hline $\mathbf{9 0}$ min & $2.73 \pm 0.22$ & $4.85 \pm 0.51^{* x y}$ & $2.67 \pm 0.30$ & $4.51 \pm 0.27^{* x z}$ \\
\hline
\end{tabular}

All values by Student's $t$-test, significant at $\mathrm{p}<0.05$, and $S E M=$ standard error mean. ${ }^{*} \mathrm{p}<0.05$ versus baseline of the respective treatment, ${ }^{\mathrm{x}} \mathrm{p}<0.05$ treatment versus control, ${ }^{\mathrm{y}} \mathrm{p}<0.05$ extract versus tramadol, ${ }^{\mathrm{z}} \mathrm{p}<0.05$ extract versus tramadol and extract, tramadol versus tramadol and extract was not significant at all time points.

Table 4: Mean values of maximal possible analgesia (mean \pm SEM) in Eddy's hot plate.

\begin{tabular}{|lllll|} 
Time & Group 1 & Group 2 & Group 3 & Group 4 \\
\hline $\mathbf{3 0}$ min & - & $37.28 \pm 6.19^{* \mathrm{x}}$ & $11.0 \pm 7.73^{*}$ & $33.35 \pm 5.72^{* \mathrm{y}}$ \\
\hline $\mathbf{9 0}$ min & - & $33.84 \pm 5.78^{* \mathrm{x}}$ & $9.28 \pm 4.21^{*}$ & $29.46 \pm 6.46^{* \mathrm{y}}$ \\
\hline
\end{tabular}

All values by Student's $t$-test, significant at $\mathrm{p}<0.05$, and $\mathrm{SEM}=$ standard error mean. ${ }^{*} \mathrm{p}<0.05$ treatment versus control, ${ }^{\mathrm{x}} \mathrm{p}<0.05$ extract versus tramadol, ${ }^{\mathrm{y}} \mathrm{p}<0.05$ extract versus tramadol and extract, tramadol versus tramadol and extract was not significant at all time points.

\section{DISCUSSION}

Tail-flick and hot-plate methods are used to evaluate central analgesic activity of a drug. ${ }^{16}$ Tail-flick method exhibits spinal reflexes to nociceptive stimulus whereas supra-spinally organised responses are elicited by the hotplate method. Both these methods employ thermal stimuli. $^{17}$
When compared to the basal reaction time within each group in the tail-flick method, all groups, except the control group, showed significant difference at all time intervals. Duration of the reaction time observed was highest for group IV (tramadol and extract treated rats). The reaction times observed in group IV differed significantly from group III (extract treated rats) at all time intervals, however, the difference was statistically 
significant only at $30 \mathrm{~min}$ when compared to group II (tramadol treated rats). On comparing group II (tramadol treated rats) and group III (extract treated rats), tramadol treated rats exhibited slightly longer reaction time. However, the difference in reaction times between groups II and III was not statistically significant at all time intervals. Hence, extract was comparable to tramadol at all time intervals (Table 1).

Figure 1 depicts the analgesic effects of the 3 test groups as shown by the MPA values. The analgesic effect was evident and reached its peak by 30 mins in all test groups. The analgesic effect was highest for group IV (tramadol and extract treated rats). There was a decreasing trend in the MPA values at the successive time intervals for all groups. The MPA achieved by the extract was comparable to tramadol at the $30^{\text {th }}$ minute. However, it decreased significantly at 60 and 90 minutes compared to tramadol.

Tramadol is a centrally acting synthetic opioid analgesic. ${ }^{18}$ Centrally acting analgesics act by increasing threshold for heat and pressure. Thermal stimulus used in the tail-flick method to induce pain is specific for centrally mediated nociception. ${ }^{4}$ Therefore, the ability of the methanolic extracts of galls of QI to prolong the reaction latency to pain thermally induced in rats suggests that the extract has some central analgesic activity.

Methanolic extract of galls of QI failed to increase the reaction time of rats in hot plate method in this study. The tramadol (group II) and the tramadol and extract (group IV) treated rats showed a significant increase in the reaction time when compared to the basal reaction time of their group respectively. On comparing groups II and IV, there was no significant difference in the analgesic effect displayed by both the groups at any time interval.

Graph 3 depicts the analgesic effects of groups II (tramadol), III (extract) and IV (tramadol and extract) as shown by the MPA values. Analgesic activity displayed by groups II and IV was as its peak at 30 minutes. It declined during the successive time intervals. However, the rate of reduction in MPA seen from 60 minutes to 90 minutes was more as compared to the reduction in MPA from 30 minutes to 60 minutes. There was no significant difference in the MPA between groups II and IV as seen in Table 4. Methanolic extract of galls of QI failed to elicit analgesic activity in the hot plate method.

In the hot plate method, the plate heated to a constant temperature produces two behavioural components that can be measured in terms of their reaction times, namely paw licking and jumping. Both are considered to be supra-spinally integrated responses. ${ }^{19} \mathrm{~A}$ failure in the inhibition of these responses by the extract indicates that it might not be acting at the supra-spinal level.

The analgesic activity seen in our study can be correlated to the findings seen in the study by Fan et al. ${ }^{4}$
The analgesic activity exhibited by various alkaloids, flavonoids, steroids and tannin isolated from medicinal plants has been noted. ${ }^{20}$ Phytochemical screening of galls of QI has revealed tannin to be its major constituent, comprising $60 \%$ of its constituents. ${ }^{21,22}$ Studies have reported the role of tannin in providing antinociception. $^{23,24}$ Tannin has been suggested to inhibit prostaglandin synthesis. $^{25}$

Based on the observations made in our study, the probable mechanism of analgesia exhibited by tannin is spinally mediated.

This study evaluated the analgesic effect of a single dose of the methanolic extract of galls of QI. Therefore, dosedependent response was not evaluated in this study, which can be considered as a drawback of this study. Further studies need to be carried out to evaluate the analgesic response at different dosages of the extract.

\section{CONCLUSION}

In conclusion, the methanolic extracts of the galls of QI showed analgesic activity in the tail-flick method but failed to do so in the hot-plate method. Also, studies need to be carried to investigate the mechanism by which the active compounds in the extract bring about analgesia.

\section{ACKNOWLEDGEMENTS}

I would like to thank the Head of Department and staff of Pharmacognosy, Bapuji Pharmacy College, Davangere for their inputs on extraction procedure. Dr. Kazi Nisar Ahmed, animal house in charge in Dept. of Pharmacology, JJM Medical College, Davangere. Dr. Latha S, Dr Krishnagouda Patil, Dr Harish Kumar and Dr Veena H, Postgraduates, Dept. of Pharmacology, JJM Medical College, Davangere.

\section{Funding: No funding sources}

Conflict of interest: None declared

Ethical approval: The study was approved by the JJM Medical College

\section{REFERENCES}

1. Merskey H. Pain terms: a list with definitions and notes on usage. Recommended by the IASP Subcommittee on Taxonomy. Pain. 1979;6:249-52.

2. Tripathi KD. Essentials of medical pharmacology. Jaypee Brothers Medical Publishers Ltd; 2013: 1973.

3. Venturelli PJ, Fleckenstein AE. Drugs and Society. Jones \& Bartlett Learning; 2017.

4. Fan SH, Ali NA, Basri DF. Evaluation of analgesic activity of the methanol extract from the galls of Quercus infectoria (Olivier) in rats. Evidence-Based Complementary Alternative Med. 2014;2014:976764. 
5. Evans WC. Trease and Evans Pharmacognosy, International Edition E-Book. Elsevier Health Sci; 2009.

6. Dhiman AK, Kumar A. Ayurvedic drug plants. Daya Books; 2006.

7. Vermani A. Screening of Quercus infectoria gall extracts as anti-bacterial agents against dental pathogens. Indian J Dent Res. 2009;20(3):337-9.

8. Summit D. Standardization and Preclinical Studies on 'Kakadshringi': Leaf Galls Used in Ayurvedic System of Medicine. Int Conference Exihibition On Analytical Bioanalytical Techniques. 2010.

9. Kaur G, Hamid H, Ali A, Alam MS, Athar M. Antiinflammatory evaluation of alcoholic extract of galls of Quercus infectoria. J Ethnopharmacol. 2004;90(2-3):285-92.

10. Basri DF, Fan SH. The potential of aqueous and acetone extracts of galls of Quercus infectoria as antibacterial agents. Indian J Pharmacol. 2005;37(1):26.

11. Tayel AA, El-Sedfy MA, Ibrahim AI, Moussa SH. Application of Quercus infectoria extract as a natural antimicrobial agent for chicken egg decontamination. Revista Argentina de Microbiologia. 2018;50(4):3917.

12. Kumar S, Dubey D. Evaluation of Quercus infectoria (galls) extracts for the management of diabetes. Int J Pharm Pharm Sci. 2016;5:1948-54.

13. Aivazi AA, Vijayan VA. Larvicidal activity of oak Quercus infectoria Oliv. (Fagaceae) gall extracts against Anopheles stephensi Liston. Parasitol Res. 2009;104(6):1289-93.

14. Azizi S, Pirbalouti AG, Amirmohammadi M. Effect of hydro-alcoholic extract of Persian oak (Quercus brantii) in experimentally gastric ulcer. Iranian J Pharm Res. 2014;13(3):967-74.

15. Patil K, Reddy SK. Dose comparative evaluation of analgesic activity of simvastatin in wistar rats. National J Physiol Pharm Pharmacol. 2019;9(6):4725.

16. Sewell RD, Spencer PS. Antinociceptive activity of narcotic agonist and partial agonist analgesics and other agents in the tail-immersion test in mice and rats. Neuropharmacology. 1976;15(11):683-8.
17. Chapman CR, Casey KL, Dubner R, Foley KM, Gracely RH, Reading AE. Pain measurement: an overview. Pain. 1985;22(1):1-31.

18. Grond S, Sablotzki A. Clinical pharmacology of tramadol. Clin Pharmacokinet. 2004;43(13):879-923.

19. Espejo EF, Mir D. Structure of the rat's behaviour in the hot plate test. Behavioural Brain Res. 1993;56(2):171-6.

20. Lim TK. Edible medicinal and non edible medicinal plants. Modified Stem Roots Bulbs. 2014;9:374.

21. Shrestha S, Kaushik VS, Eshwarappa RS, Subaramaihha SR, Ramanna LM, Lakkappa DB. Pharmacognostic studies of insect gall of Quercus infectoria Olivier (Fagaceae). Asian Pacific J Tropical Biomed. 2014;4(1):35-9.

22. Aroonrerk N, Kamkaen N. Anti-inflammatory activity of Quercus infectoria, Glycyrrhiza uralensis, Kaempferia galanga and Coptis chinensis, the main components of Thai herbal remedies for aphthous ulcer. J Health Res. 2009;23(1):17-22.

23. Abdulmalik IA, Sule MI, Yaro AH, Abdullahi MI, Abdulkadir ME, Yusuf H. Evaluation of analgesic and anti-inflammatory effects of ethanol extract of Ficus iteophylla leaves in rodents. Afr $\mathrm{J}$ Tradit Complement Altern Med. 2011;8(4):462-6.

24. Das BK, Al-Amin MM, Russel SM, Kabir S, Bhattacherjee R, Hannan JM. Phytochemical screening and evaluation of analgesic activity of Oroxylum indicum. Indian $\mathbf{J}$ Pharm Sci. 2014;76(6):571-5.

25. Mali AA, Bandawane DD, Hivrale MG. Evaluation of anti-inflammatory and analgesic activity of methanol extract of Cassia auriculata leaves. Pharmacologia. 2013;4(2):117-25.

Cite this article as: Raichurkar AP, Reddy SGH. Evaluation of analgesic activity of the methanol extract from the galls of Quercus infectoria alone and as an adjuvant in wistar rats. Int $\mathrm{J}$ Basic Clin Pharmacol 2020;9:701-5. 